\title{
PSYCHOTHERAPY AND SCHIZOPHRENIA: AN ANALYSIS OF REQUIREMENTS OF AN INDIVIDUAL PSYCHOTHERAPY FOR PERSONS WITH PROFOUNDLY DISORGANIZED SELVES
}

\author{
PAUL H. LYSAKER \\ Roudebush VA Medical Center and the Indiana University \\ School of Medicine, Department of Psychiatry, \\ Indianapolis, Indiana, USA \\ JOHN T. LYSAKER \\ Department of Philosophy, University of Oregon, \\ Eugene, Oregon, USA
}

Many emerging views of outcome from schizophrenia emphasize that persons must recover a sense of their own identity, agency, and personal worth. While this is intuitively appealing and consistent with a wide range of literature, it raises the issue of how best to facilitate this. In this article we explore how integrative psychotherapy might address issues of narrative and recovery from schizophrenia among persons experiencing more profound levels of disorganization. Illustrated with a case example we explore in particular the barriers posed to psychotherapy by a client's cacophonous selfpresentations. We then describe techniques from an integrative perspective that might help therapists enter dialogue with persons so afflicted. Our claim is that psychotherapy can revitalize dialogues within the client and between the client and others that enable the reconstruction of a personal narrative from which a life plan might be articulated.

Many have observed that schizophrenia involves a profound diminishment in the ability to experience and represent one's life as an evolving story (Laing, 1978; Lysaker \& Lysaker, 2001; 2004; Parnas \& Handest, 2003, Sass, 1994; Searles, 1965). This may involve the generation of narratives that lack conceptual and temporal organization (Gallagher, 2003; Holma \& Aaltonen, 1998; Minkowski, 1987) and/or self-presentations without agency or meaningful interpersonal connections (Davidson, 2003; Kline, Horn, \& Patterson, 1996; Lysaker, Wickett, Wilke, \& Lysaker, 2003). Beyond merely confused communication about concrete facts, these diminishments contribute to a sense of self riddled with anguish and lacking depth and richness.

Recently, there has been renewed interest in the potential of psychotherapy to help persons with schizophrenia recover the kind of self regard lost or displaced with the onset of schizophrenia (Lysaker, Lancaster, \& Lysaker, 2003). These suggestions are consistent with the traditional aims of both the psychotherapy of schizophrenia (Fenton, 2000; Fromm-Reichmann, 1954) and psychotherapy in general (Neimeyer \& Raskin, 2000). They are also consistent with literature on the relationship of narrative with 
interpersonal and general psychological health (Dimaggio, Azzara, Salvatore, Catania, Semerari, \& Hermans, 2003; McAdams, 2001; Polkinghorne, 1995) and with observations that changes in selfconcept occur with recovery from mental illness (Davidson, 2003; Roe \& Chorpa, 2003; Young \& Ensign, 1999).

At present, however, it remains unclear how therapy will help persons with schizophrenia recover a storied sense of their lives replete with a sense of personal agency, particularly among those with the greatest level of disorganization. Previously, we suggested that psychotherapy may help persons suffering from schizophrenia frame and discuss problems, mourn, evolve hopes and enact change (Lysaker, Lysaker \& Lysaker, 2001). Yet, what kinds of narrative capacities are required to synthesize and support these gains into a coherent life story? In this article, we will expand upon previous work and focus on how one might profitably work with persons with schizophrenia compromised by profoundly disorganized self-understandings. We begin with a case study describing someone with such levels of disorganized self-experience. Employing a dialogical theory of the self, we offer a conceptualization of these anguished states and formulate some psychotherapeutic principles for such cases, drawing further examplesfrom the case study.

\section{Disorganized Selves in Schizophrenia A Case Illustration}

Purcell is a man in his 40s with schizophrenia, disorganized subtype. At the onset of his psychotherapy his speech was loud and rapid with frequent loose associations and occasional neologisms. His affect ranged from blunted to inappropriate, with occasional poorly modulated explosions of anxiety and fear, seemingly untied to the environment. He believed others could enter his body and cause him pain, heard voices around him, and believed that he was persecuted by an "other" who seemed to be everyone around him. He had been hospitalized for over 20 years in an institution where he received what appeared to be custodial care. For that period of time, he reported having no close friends, steady unemployment, and continuous alienation from family. He had a history of childhood sexual trauma and a host of legal problems in adolescence and adulthood. Physically, he was in poor health and suffered from chronic pain. Neurocognitive testing indicated profound deficits in verbal memory and executive function. He came to psychotherapy following a transfer from the inpatient hospital to a group home due to that institution's diminishing resources. Throughout his psychotherapy he was prescribed a second generation atypical medication at the same dosage.

When Purcell spoke about past and present daily events, it was nearly impossible to follow him. There were few references to a temporal sequence of events and little to no mention of others by name. When he spoke of himself, it was often unclear how the various things he said cohered. The following is taken from an interview shortly after he began therapy:

Because it's hard finding yourself again. Anybody can come up with a question and turn the whole picture around. Anybody can find an answer and they can't stand you. But if you got something to hold, that you can hold against them, that'll tear you to pieces and tear them to pieces. And somebody may be sticking up for your life on one side, and on the other side it may be your own family. They don't want them to take your part. 
Here, from the same interview, he refers to a past event:

I went absent without giving notice a few times from the service while I was in there. I don't know why ... it was my fault, because either way if I didn't go absent without leave, if I stayed in there I was in great danger. I already had something wrong with me, accidents that were inflicted and accidental, and in ways of life I had a challenge because there was a great opportunity going on then by surrounding companies and stuff. A person can make a living outside the company and don't have to work for the company, which is bad in one sense and good on the other sense. This is mixed up, but I can't align the stories straight because they're all different time frames.

Later he describes spending time at a pool hall:

The old man would tell of his travels to Athens and uh ... where he was born at. And ... it's always slander back and forth if you tell them where you been and who you associated with. They don't keep everybody up in high spirits or high standards, they look down on each other. That, so all that tore me apart, so I just went to drinking and drugging. Uh . . . it seems like I was a conscientious objector then, because I think that if the military knows you're not fit for the military, they ain't gonna jeopardize an American, right? And if there's reason why ... see, I used to run for the March of Dimes ... Telethon ... Marathon.

\section{A Dialogical Conceptualization of Cacophonous Selves}

In Purcell we find a person with schizophrenia strikingly unable to narrate the story of his life. He is in pain, feels lost, but even these states are something his speech manifests rather than articulates. In order to think about how psychotherapy might help persons with these issues, we first ask how and why people like Purcell have such difficulty narrating the story of their lives.

Synthesizing literature from philosophy, the social sciences, and literary criticism, Hermans $(1996,2004)$ has suggested the self and narratives of the self can be conceptualized as the product of ongoing conversations both within the individual and between individuals and others. According to this model, different aspects of the self can be labeled self-positions, to emphasize their semiindependence. In a manner that gives one a sense of self, they are thought to interact with one another, both within and between persons. For example, one might regard oneself as a "brother" and a "father," thus giving one a sense of internal complexity that simultaneously relates one to others (e.g., one's siblings, parents, and children).

Importantly, interaction among self-positions is not random but involves the continuous switching or establishment and dissolution of temporary hierarchies among self-positions. For example, in response to overlapping situations, say, a chance encounter, a memory, and an ensuing joint project, several self-positions might come into play and require ordering, such as self-as-friend, self-as-compassionate, and self-as-social critic. In our view, a kind of internal richness accrues when movement among these positions is fluid and coherent. And it is this kind of movement that forms the basis of our self-conscious self-presentations, for example, in life stories (Lysaker \& Lysaker, 2005). 
In other words, one tells the story of one's life by drawing upon the sense of self one receives through dialogical movement among self-positions.

With this general conception in mind, we have argued that disruptions in the shifting of the hierarchies of self positions could result in at least three forms of impoverished personal or second-order narratives that closely parallel what is seen in schizophrenia (Lysaker \& Lysaker, 2002). If the hierarchy of self-positions were to ossify such that periodic shifts proved impossible among the hierarchy of the dialogical self, we have suggested that either of the first two forms of impoverished narrative might occur: a barren or a monological personal narrative. Barren narratives might include stories without details or affects, where conversation within the self is largely no longer taking place. Monological narrative would include stories where events are continuously framed by a singular never shifting organization resulting in the familiar stories within schizophrenia of self as the subject of persecution or container of grandiosity. If, however, no order were given to movement among self-positions, the third form of disorder might ensue: a cacophony. Here one would expect disorganization with multiple aspects of self or self-positions present, all speaking at once or without order. Various self-positions might interrupt one another, or comment without reference to one another, resulting in a series of disjointed utterances. Of note, this is not to say that biological forces are not at work in the development and course of schizophrenia. In previous work (Lysaker \& Lysaker, 2001) we have noted that in the tradition of Blueler (1911) it is possible that disturbances in associative processes could compromise the dialogical self. Disturbances in associative processes, or the tendency to inadvertently "jump" over ideas naturally associated with one another when thinking would disrupt movement between various aspects of self. Furthermore positive and negative of schizophrenia symptoms could also erode the capacity for internal and interpersonal conversation, compromising dialogical capacity (Lysaker \& Lysaker, 2004).

We think Purcell offers such a cacophonous personal narrative. In the above excerpts, he presents himself as unable to sustain a sense of himself in the presence of others, stressing that whatever might sustain him eventually devours him and those around him: "anyone can come up with a question and turn the whole picture around." $\mathrm{He}$ cannot recall his past in a manner that keeps time periods distinct leaving his story as jumbled as his sense of self. In the third excerpt, this jumble becomes starkly apparent as his recounting moves in seemingly random fashion from being a patron at a pool hall to being someone no longer in military service who might be considered absent without leave to being a volunteer who, he further relates, was honest and thereby became mentally ill: "My honesty was what took into this mental illness."

From a dialogical perspective, we find a marked inability to move meaningfully among self-positions once they enter into the situation. When he says, for instance: "I don't know why . . . it was my fault, because either way if I didn't go absent without leave, if I stayed in there I was in great danger," we find self positions such as "self-asguilty," "self-as-not guilty" and "self-as-imperiled" following one another in such a manner that no clear point can be understood to be made about this event. It is as if there are persons speaking in a play and not only uttering fragments but also uttering those fragments without awareness of what another might have just uttered. In our view, the problem is less that Purcell entertains so many self-positions than that he is unable to order them. All of us often move rapidly through multiple self-positions, sometimes 
simultaneously. For example, meeting someone at a restaurant who reminds us of an adolescent love that ended with parental disapproval could instantly evoke numerous self-positions such as self-as-diner, self-with-new-acquaintance, self-as-teenager, self-asunfulfilled and self-as-friend. In most cases, it would be necessary to prioritize or order which positions should orient behavior, in both intrapersonal and interpersonal terms. Purcell, though, seems unable sustain such as an order. Rather than producing a personal narrative with a stable protagonist moving purposefully through defined contexts, his self-presentations involve wild switches in self-positions and contexts that produce confusion for all involved.

\section{Psychotherapy in the Face of Cacophony}

\section{The Initial Difficulties}

To begin, the eruption of cacophony in a client's personal narrative poses immediate challenges for psychotherapy. Conversations where roles and affects and desires contradict or exist in isolation from one another may render any immediate synthesis impossible. It can give the impression of an absence of meaning. Therapists may see little point to pursuing conversations amid a disjointed array of thoughts and emotions, and they may become anxious and feel inclined to flee. Some may even think that provoking such confusion could be dangerous to the client.

In such cases, if there is a first step to individual psychotherapy, it is to not flee. Because meaning is not immediately manifest does not mean conversation is pointless. Commitment to staying with the client is not sufficient, however. The psychotherapist must also resist imposing order upon client's self-presentations. Therapists must, for instance, resist providing a surrogate sense of order by filling in details, drawing connections, and weaving a story from out of the tumble of remarks one hears. They should avoid regarding client's speech as the paradoxically precise expression of a mad world, thus relocating the narrative's disorder in the field of social relations. They should also resist simply regarding client's remarks as the symptoms of a disordered neurochemistry, bringing an order to the narrative through a third person explanation of its origin, much as one orders seemingly odd symptoms by locating their cause.

While clients with cacophonous selves may be protesting injustice and/or suffering from biologically based conditions, they nevertheless are relatively unable to compose the story of their lives, even as it unfolds. Moreover, it is not as if addressing neurological anomalies or unjust social conditions provides a coherent life story or delivers the ability to compose one. In each case, that work remains to be done, but by the client, not the therapist. To impose a story, even if it contains elements of truth may convey the message that the therapist, not the client is responsible for the story telling. Organizing a clients' stories for them may lead them to conclude that only others should tell their stories, that is, that their stories are not principally theirs. To our minds, this suggests a second principle for psychotherapy with clients like Purcell: avoid resolving their confusion for them.

But how does one help them begin to weave their own narrative? While it may be difficult to directly discern what the client is expressing, it may be possible to note what is not being expressed or what it is missing. For instance, while it may be impossible to 
decipher what the client felt last evening, it may be clear that he or she felt no emotional security. Or, one may find that whenever contact with others is described it is accompanied by anxiety and confusion, such that no meaningful story of interpersonal relations ever evolves.

Alongside noting and sharing absences, the therapist also may begin assisting clients to find identifiable aspects of themselves or self-positions hidden within the flood of material they have brought to session, for example, self-as-abandoned or self-as-hardworker. In other words, at the beginning of therapy, one can identify and reinforce selfpositions that at some point in the future could order and stabilize movement among selfpositions. Borrowing from the tradition of humanistic psychotherapy this can involve a reflection about a briefly glimpsed aspect of self that fades after being recognized, for example, that one is angry, or frightened, or underappreciated. Importantly, because clients at this stage remain acutely sensitive to power differentials, one should articulate self-positions that privilege the client's perspective.

The following excerpt illustrates the process of reflection about a briefly glimpsed aspect of self in a cacophonous presentation. It was taken from Purcell's third month of individual psychotherapy. Of note, the sessions from which all material in this article was drawn, lasted 30 minutes, and were audiotaped and later transcribed.

Purcell: Well Catholics has got its own sort of people that are dedicated.

And they don't try to ask for help, Catholics don't. But they try to understand the, well it's just like old Italian and the new Italian. The old Italian thinks of things I never thought of. That's like prerequisite to them, then they tell you one thing means a whole bunch of things and that's a warning you know. If you do something, if you're studying to know what you should know, to know for yourself what is true, you ain't never going to get what is true but you ain't never going to get stuck in teaching because to study in teaching, there ain't time for it. It was a rush job. I'm almost like a dog in some respects and when they start putting out human beings like me on the field, it frightens me.

Therapist: It frightens you.

Purcell: Yeah because they're up to my game and I'm just trying to figure out why I'm in the middle of the game but I'm trying to play it as meaningful as I can, trying to go for that gold you know.

Therapist: Being a small boy in parochial school was overwhelming.

Purcell: Well just being a man. It's like walking over to somebody else's place.

Therapist: It's not comfortable and it's not yours?

Purcell: Well see some protect the catholic schools better than they protect the class and some, your heritage, everybody's background is ethnic but they don't want you to hang onto that. It's like you may want to cross the fence but that fence is still there when you move. Therapist: It was impossible to fit in?

Purcell: Well as far as having paperwork, I failed. But as far as carrying it out and doing what was right on the side of them, it's hard to put to practice unless you're correct and one time before I even said a word, for all my mistakes I was corrected. So there's ways of using forcefully and directly criticism, the "should" and "should nots." Some tests results say it doesn't go that way and the harder you try, they let you go that way.

In this excerpt, the therapist refrains from actively synthesizing the client's remarks into a coherent story, one that has a beginning, middle and end. Rather, the therapist identifies and articulates feelings or aspects of self otherwise embedded in the rush of statements, aspects that, if they evolved, might order a sequence of self-positions, 
for example, self-as-outsider, and bring narrative continuity to Purcell's recollections. The point isn't necessarily to find the "right" self-position but to find and ask about one without trying to organize other points around it. For instance, contained within the metaphor of the fence that moves, are several different qualities of self-experience that could be interpreted. While the therapist reflects that maybe Purcell found it was difficult to fit in, he could have just as easily reflected the experience of self-as-victim, self-asenraged, or self-as-justified in rebellion.

An important question though that arises here is how the therapist chooses which self-position to bring to the foreground. Principles that may guide therapists in these decisions include looking for recurring self-positions and noticing without moral valuation the presence of those self-positions. Underscored here is again that therapists listen to clients and are not seeking to bring their own story to bear on the seeming disorder. Evidence that one has more or less correctly identified self-positions of importance could then be found in the degree to which the client recognizes the reflection. Reflections deemed accurate to some degree can then be remembered by the therapist and applied again later in the session or in future sessions, creating meaningful bridges between and within sessions.

\section{Intermediate Phases}

Initially we suggested that when working with such disorganized persons, the therapist should not tell the client's story for him or her, but should begin to hear and identify possible aspects of the client's self. The next stage involves having the client expand upon self-positions that have been brought to the fore. After a period of discovery regarding recurring self-positions, the client may begin to elaborate how these positions may exist alongside one another. While there is no synthesis here, there may be the development of self-positions that could lead to the establishing of new hierarchies. This added focus may involve a singular idea about the self expressed across two or three sentences rather than two or three words. It may also include statements involving a relation between two or more self-positions without explicit reflection upon that relation. In this phase the therapist should continue reinforcing various self-positions as they emerge without forcing a synthesis upon them but take note of emerging relations among them, for example, as between self-as-special and self-as-failure. Here one view might be that the therapist is promoting a capacity to monitor shifting qualities of self-experience. As an illustration the following is from around the twelfth month of Purcell's therapy.

Purcell: I mean if I lose a bunch of ground it could be in-persistence, it could be in my character ... maybe I put the blame on somebody else or I think you put the blame on me. I think if I was blameless you wouldn't associate with me and take care of me then. If I take the blame and I don't know what I'm taking the blame for then it's a rough road. Therapist: So you need the blame or I wouldn't associate with or take care of you? Purcell: Well its just I believe that you wouldn't stick your neck out for me. I mean, its like coaxing ... coaxing a bird out of its cage, like a cat.

Therapist: So you're the bird in the cage and I've coaxed you out?

Purcell: You may be the cat. That's what I ... I see that all the time

Therapist: Someone who would devour and hurt you?

Purcell: There's wolves in sheep's clothing waiting to bite and devour. 
Therapist: If you learned it was safe would it still be difficult to come out of the cage?

Purcell: Yes ... man has scared me into the cage, society scared me into the cage, things dictate to me in the cage. I cannot go out there and expect to endure or persevere.

In this excerpt, Purcell's cacophony continues, but now two aspects of self exist in close proximity to one another with some reference to one another. It seems evident that he is needy yet vulnerable. He fears both abandonment and being hurt by others. Both "self-as-needy" and "self-as-vulnerable" exist within him, though it is unclear how one affects the other. It seems that Purcell is still unable to entertain both positions at once or negotiate interaction among them. In other words, it seems that Purcell is still unable to pursue an internal dialogue about who he is.

Here we observe two larger and closely related phenomenon of crucial importance. First in the cacophony of Purcell's awareness, self-positions are emerging in the context of a relationship. As dialogue has progressed over the course of a year, the therapist is now necessarily recognized as someone listening but also as someone likely to respond in a particular manner. With growing dialogue has come awareness of the other. The therapist though is not seen as a generic or nameless other, but as a specific partner in dialogue: a tyrannical and predatory being not to be trusted. While this poses a number of immediate problems, what is novel and evidence of progress is that Purcell has cast the therapist here into a defined position. There is a conversation occurring here with a specific other.

A second and related point is that in Purcell's cacophony, self-positions are arising in multiple places including those in social relationships. In other words, the resolution of Purcell's cacophony is not being experienced purely as a matter of inward discovery. In line with many of the principles of dynamic psychotherapy, the relationship is a place for discovery. In contrast though, to processes commonly in the treatment of neurosis or personality disorders, Purcell seems to be making nearly all of his discoveries within the dialogical person of the therapist. A year after beginning therapy he is asserting that the therapist is "loving," "sad," "angry," "stupid," and "predatory." In other words, he appears to have to understand these self-positions as existing in the therapist before being able to attempt to interiorize these discoveries.

In response to the evolving relationship and Purcell's growing discovery, the therapist is again accepting of his perception and resists the urge to flee or correct Purcell. Called a predator, for instance, the therapist does not object or see this perception as something to be corrected. He does not use, for example, the cognitive tack of examining the evidence that supports such as assertion. The therapist instead helps Purcell to elucidate this experience. The therapist feels the discomfort and a sense of being trapped but using awareness of his own countertransference asks more about Purcell's experience, leading Purcell to himself talk about feeling vulnerable. A real danger here is that if the therapist protests that he would never be a predator he might well convey to Purcell that he would reject him, if he (the therapist) learned that Purcell experienced aspects of self which were predatory, thus blocking a path to awareness of this.

\section{Advanced Phases}

In what we've called the beginning and intermediate stages of psychotherapy for persons with disorganized selves, we have so far suggested that clients begin to experience 
individual aspects of themselves alone and then in relation to one another. In advanced phases we find clients begin to move in an orderly fashion among self-positions, to experience comprehensible exchanges within the self, and to articulate self-positions about self-positions, with the final result that they begin to narrate their lives in an initially meaningful manner.

In advanced phases of therapy, the primary task remains facilitating growing internal conversations. This may mean not only noticing how different aspects of the client's self exist in relation to one another but also recalling and recollecting previously mentioned material and inquiring about how they relate to present material. It may also involve direct questions concerning how the therapist is being experienced in relation to the different aspects of self that are emerging. Consider the following excerpt from the twenty-fifth month of psychotherapy:

Purcell: If you know somebody cares about you and you try to respect them. Because you want to invade their space and you tend to get on the beaten ... I have an ignorant mind. My lifestyle goes in spurts. Anybody that wants me to behave doesn't allow anything for me, they want to know if I am that type of guy, it is hard to say that you have forgiven me and that you don't hold nothing against me, but eh, there is always that good Samaritan that is taking better care of themselves than they would take care of me. That is my outlook on life. Therapist: Am I like a good Samaritan?

Purcell: I wasn't going to accuse you, I mean we all can, we can all set out to make another person accused or make them do something that they don't want to do. That's everything. Therapist: So you are not sure what to make of me?

Purcell: Well, I can give my psychiatrist power, or I can overwrite, that's overlooking the true to life person, that is me, that is my confession, I overlook the true to life person, because I feel like I can't fit in, or I am not welcome.

In this excerpt, in contrast to earlier stages of treatment, Purcell shows a kind of selfawareness that compares aspects of his character and articulates a general outlook on his life. His relationship with the therapist has also deepened. His assertion that the therapist is a "Good Samaritan" is perhaps not without a context and may relate to the current moment. Though not pursued by the therapist, this assertion may well be an ironic remark about how the therapist is not responding to Purcell's barrage of angry insults. Purcell thus is responding to the therapist in the present while being aware that his perceptions of the therapist may not be fully accurate, but distorted by his own anguish.

Also revealed here, is that alongside the development of the therapeutic alliance, Purcell is thinking about himself in relation to others. There is his observation, for instance, that his life is one of spurts owing to his "ignorant mind." Purcell recognizes that he often drives away those who try to care for him by invading their space and this returns him to the well-beaten path he describes as characterized by spurts. He then reflects on the difficulty of repairing those relationships and observes that others want to know if he is "that type of guy," presumably, one who invades their space. He also acknowledges, however, that he resists being asked to "behave" and that he doubts he has been really forgiven. Strikingly, reflections made more than 20 months earlier are thus again present but now not in the form of isolated fragments. They are instead integrated within more complex self-positions such as self-as-cared-for, self-as-invasive, and self-as stuck in a rut, and self-as-ignorant. A coherence to larger movement within therapy is 
thus in evidence along with the beginning of a genuine dialogical capacity for Purcell which enables him to bring a kind of coherence to his life.

In reflecting on this pattern generated by his self-described ignorance, Purcell also offers an outlook on his life as storied. He attributes a general selfishness to others: “ . . better care of themselves than they would of me." His lifestyle is one of spurts because others prefer to take care of themselves rather than him, which, in Purcells' case, means that they opt not to forgive him but to protect themselves. This turn of thought is interesting because it provides a reason for the events of his life. Others are responsible for the beaten path upon which Purcell finds himself again and again. This externalization intensifies when he extends the figure of the not quite so Good Samaritan into a more general principle. Each individual can make others do what they don't want to do. "That's everything," he says, seemingly suggesting that others, his therapist included, might be making him do some of the things he formerly characterized as ignorant.

Purcell's reflections do not end here. Shortly thereafter, he rejects in a selfdescribed "confession" the powerlessness implicit in his general outlook, and takes responsibility for his life: "I overlook the true to life person, because I feel like I can't fit in, or I am not welcome." In our view, this elaborates the position of "self-as-ignorant," and in a way that does justice to the true dilemma he recurrently faces. Because he feels unwelcome or even alienated, and thoroughly fears rejection, he overlooks the true character of those he engages (perhaps even himself), thus compromising his relations.

At this point, it is not as if Purcell has acquired a thoroughly integrated personal narrative, nor does he demonstrate sophisticated dialogical capacities. For example, he draws no connections between his aggressiveness and his feeling unwelcome, and his fear of rejection is only indirectly noted in the latter. Nevertheless, severity of the initial disorganization has begun to wane. Moreover, Purcell now can discuss, both with himself and his therapist, how he feels, what he thinks is wrong in his life, what works, and subsequently he can mourn, hope, and enact. Put another way, he now appears able to begin thinking about his life, considering whether or not he should or alter his thinking and/or behavior. Thus he is beginning to conceive of himself as an agent in a life whose course he can narrate.

In some literature on the role of agency in recovery, an emerging awareness of agency is suggested as a transforming and possibly joyful event. With schizophrenia, our experience is otherwise. Mirroring the literature on awakenings and despair (Duckworth, Nair, Patel, \& Goldfinger, 1997), we find that greater awareness is often accompanied by feelings of loss, persistent failure, and even trauma. These advanced stages thus do not mark the end of therapy. Here, though, coherent and constructive discussion about one's life is possible and the therapy of persons with schizophrenia begins to resemble the therapy of persons without psychoses who are seeking to rebuild their lives in some significant manner.

\section{Commentary and Limitations}

With reference to a single case, we have asserted that in profoundly disorganized persons with schizophrenia we find dialogues within the self and between the self and others that lack sufficiently ordered movements, and thus prove incomprehensible. We asserted that psychotherapy's initial tasks are to help clients find and expand the voices of individual 
self-positions, to notice that individual self-positions exist in relation to one another, and to facilitate the emergence of a fluid order of self-positions. This takes place within a developing therapeutic relationship and often involves the client noticing or discovering self-positions as residing in the therapist and only later interiorizing them.

While this may be a theoretically sound account, do we find evidence in our case of improvement? Did Purcell get better? We think so. Purcell begins with no real discernable story or experience of himself, and his life appears incomprehensible to himself and others. After one year of therapy, he begins to describe himself. He says that he is "scum of the earth." He asserts he has been "obliterated" and his body "ruined beyond repair." It is a story of disaster after a year of therapy, but at least it is a story. After two years, Purcell's story is still about disaster but it contains more. Pained, he notes that he is "mostly" ruined and unsure how to deal with the potential or "parts" of him that still function. He has experiences of self as both touched and not touched by disaster and an awareness of both as simultaneously present. There are reasons for what has unfolded in his life. He notes he has sexual feelings and is ambivalent about his participation in a work program. These changes also occur as he moves from a group home into a supported apartment, his first community residence in almost two decades.

Of note, this progress was not linear. Following improvements were setbacks and after declines came progress. Thus even after two years Purcell continues to need assistance to identify self-positions and discover their relations with other positions. He has noted after a holiday absence: "when you go away I notice part of me is missing." However, following a kind of reestablishment of dialogical capacity, his therapy increasingly involves the ongoing construction of the personal narrative within which he plans his life and understands his ever more complex affects and relationships.

So how was change facilitated? How did psychotherapy help Purcell recover a narrated sense of his life? We would hypothesize that the ongoing dialogue between therapist and client may have helped the client to slowly develop metacognitive capacity, that is, the ability to think about his own thoughts and the thoughts of others. More specifically, perhaps the therapist, independent of technique, functioned as a form of prosthetic that helped Purcell to train his anguished consciousness to attend to itself and then to discover its increasing complex constituency first in the minds of others and then within. Perhaps in the manner of physical therapy, he was able to practice something fundamentally dialogical in nature, something he had lost as a result of the basic neurocognitive insults of schizophrenia and atrophy from decades in institutions. As with all initial hypotheses there are many alternative hypotheses that cannot be ruled out, however. While we speculate that there were changes in narrative that sprung from changes in metacognition, it is possible both were the result of other factors. It may be for instance, perhaps he was merely retraining himself to focus his attention by simply sitting and talking about anything on a twice a week basis as is described in the literature on cognitive retraining by Bell and colleagues (2001). Perhaps change occurred at the level of specific skills.

Finally, there are limitations to our report. Drawing from a case study we have sought to be informative and to stimulate practice and research but cannot define psychotherapy for all with schizophrenia. Further study is needed with many more with schizophrenia, including women, persons with less debilitating courses of illness, and in the early stages of illness. Also, change in the dialogical self and narrative constructions 
seems as idiographic as any other variable in social science. It has yet to be determined how best to assess this and thereby begin to know how often what was observed here occurs elsewhere. Similarly, the integrative therapy offered Purcell might be dissimilar from other forms of psychotherapy in ways not articulated here. Of note, progress was reported over several years. It is yet to be determined if there are ways to help persons recover more quickly. In short, this is a beginning and we hope our findings will be the basis for systematic projects.

\section{References}

Bell, M., Bryson, G., Greig, T., Corcoran, C., \& Wexler, B. E. (2001). Neurocognitive enhancement therapy with work therapy: Effects on neuropsychological test performance. Archives of General Psychiatry, 58, 763-768.

Bleuler, E. (1911/1950). Dementia praecox or the group of schizophrenias (Trans J. Zinkin). New York: International Universities Press.

Davidson, L. (2003). Living outside mental illness: Qualitative studies of recovery in schizophrenia. New York: New York University Press.

Dimaggio, G., Azzara, G., Salvatore, C., Catania, D., Semerari, A., \& Hermans, H. (2003). Dialogical relationships in impoverished narratives: From theory to clinical practice. Psychology and Psychotherapy, 76, 385-409.

Duckworth, K., Nair, V., Patel, J.K., \& Goldfinger, S. (1997). Lost time, found hope and sorrow, the search for self, connection and purpose during awakenings on the new antipsychotics. Harvard Review of Psychiatry, 5, 227-233.

Fenton, W. S. (2000). Evolving perspectives on individual psychotherapy for schizophrenia. Schizophrenia Bulletin, 26, 47-72.

Fromm-Reichmann, F. (1954). Psychotherapy of schizophrenia. American Journal of Psychiatry, 111, 410-419.

Gallagher, S. (2003). Self narrative in schizophrenia. In T. Kirshner \& A. David (Eds.), The self in neuroscience and neuropsychiatry (pp. 336-353). Cambridge, UK: Cambridge University Press.

Hermans, H. J. M. (2004). The dialogical self: Between exchange and power. In: Dialogical Transformation in the Psychotherapy of Schizophrenia. In H. J. M. Hermans \& G. Dimaggio (Eds.), The dialogical self in psychotherapy. New York: Brunner-Routledge.

Hermans, H. J. M. (1996). Voicing the self: From information processing to dialogical interchange. Psychological Bulletin, 119, 31-50.

Holma, J., \& Aaltonen, J. (1998). Narrative understanding and acute psychosis. Contemporary Family Therapy, 20, 253-263.

Kline, J., Horn, D., \& Patterson, C. M. (1996). Meaning and development in the interpersonal treatment of severe psychopathology. Bulletin of the Menninger Clinic, 60, 314-315.

Laing, R. D. (1978). The Divided Self. New York: Penguin Books.

Lysaker, J. T., \& Lysaker, P. H. (2005). Being interrupted: The self and schizophrenia. Journal of Speculative Philosophy, 19, 1-22.

Lysaker, P. H., Lancaster, R. S., \& Lysaker, J. T. (2003). Narrative Transformation as an outcome in the psychotherapy of schizophrenia. Psychology and 
Psychotherapy, 76, 285-300.

Lysaker, P. H., \& Lysaker, J. T. (2004). Schizophrenia as dialogue at the ends of its tether: The relationship of disruptions in identity with positive and negative symptoms. Journal of Constructivist Psychology, 17, 105-120.

Lysaker, P. H., \& Lysaker, J. T. (2001). Psychosis and the disintegration of dialogical self-structure: Problems posed by schizophrenia for the maintenance of dialogue. British Journal of Medical Psychology, 74, 23-33

Lysaker, P. H., \& Lysaker, J. T. (2002). Narrative structure in psychosis: Schizophrenia and disruptions in the dialogical self. Theory and Psychology, 12, 207-220.

Lysaker, P. H., Lysaker, J. T., \& Lysaker, J. T. (2001). Schizophrenia and the collapse of the dialogical self: Recovery, narrative and psychotherapy. Psychotherapy Research, Practice, Training, 38, 252-261.

Lysaker, P. H., Wickett, A. M., Wilke, N., \& Lysaker, J. T. (2003). Narrative incoherence in schizophrenia: The absent protagonist, neurocognitive impairments and fear of audience. American Journal of Psychotherapy, 57(2), $153-166$.

McAdams, D. P. (2001). The psychology of life stories. Review of General Psychology, $5,100-122$.

Minkowski, E. (1987). The essential disorder underlying schizophrenia and schizophrenic thought. In John Cutting and Shepherd (Eds.), The clinical roots of the schizophrenic concept (pp. 188-212). Cambridge, UK: Cambridge University Press.

Neimeyer, R. A., \& Raskin, J. D. (2000). Constructions of disorder: Meaning-making frameworks for psychotherapy. Washington, DC: APA Press.

Parnas, J. \& Handest, P. (2003). Phenomenology of anomalous self-experience in early schizophrenia. Comprehensive Psychiatry, 44, 121-134.

Polkinghorne, D. E. (1995). Transformative narratives: From victimic to agenic life plots. American Journal of Occupational Therapy, 50, 299-305.

Roe, D., \& Chopra, M. (2003). Beyond coping with mental illness: Toward personal growth. American Journal of Orthopsychiatry, 73, 334-344.

Sass, L. A. (1994). Madness and Modernism. Cambridge MA: Harvard University Press.

Searles, H. (1965). Collected papers of schizophrenia and related subjects. New York: International Universities Press.

Young, S. L., \& Ensign, D. S. (1999). Exploring recovery from the perspective of persons with psychiatric disabilities. Psychosocial Rehabilitation Journal, 22, 219-231. 